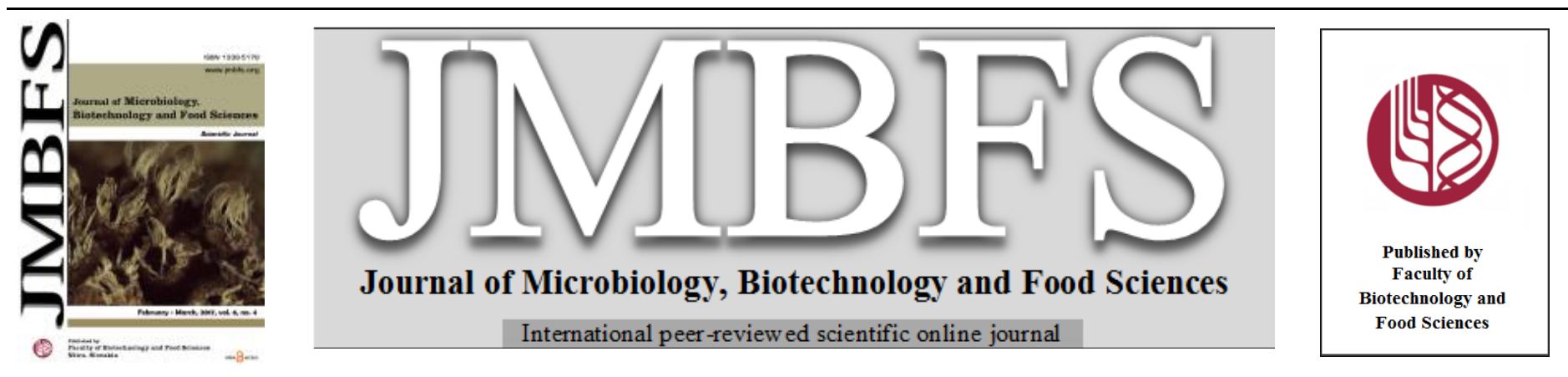

\title{
OPTIMIZATION OF INGREDIENT AND PROCESSING PARAMETER FOR THE PRODUCTION OF Spirulina platensis INCORPORATED SOY YOGURT USING RESPONSE SURFACE METHODOLOGY
}

\author{
Samadrita Sengupta ${ }^{1}$, Jayati Bhowal $*^{2}$ \\ Address(es): \\ ${ }^{1}$ IIEST,Shibpur, Senior Research Fellow (PhD), SOCSAT, IIEST, Shibpur, Botanic Garden, Howrah 711 103, WB, (+91) 9903780850. \\ ${ }^{2}$ IIEST,Shibpur, Assistant Professor, SOCSAT, IIEST, Shibpur, Botanic Garden, Howrah 711 103, WB, (+91) 9831672455.
}

*Corresponding author: jayatibhowal@gmail.com

doi: 10.15414/jmbfs.2017.6.4.1081-1085

ARTICLE INFO

Received 13. 10. 2015

Revised 4. 8. 2016

Accepted 18. 12. 2016

Published 1. 2. 2017

Regular article

OPEN $\partial_{\text {ACCESS }}$

\begin{abstract}
In this study, response surface methodology (RSM) was employed to optimize the ingredient formulation and processing parameters of Spirulina platensis incorporated soy yogurt production such as temperature, time, and amount of Spirulina platensis on the sensory evaluation responses on 9 point Hedonic rating. Besides, the physico-chemical properties such as $\mathrm{pH}$, titratable acidity, viscosity and penetration of the Spirulina platensis incorporated soy yogurt were also analysed. The analyses show that the Spirulina platensis incorporated soy yogurts have a pH from 3.43 to 5.55 , acidity from 0.64 to 2.32 (\%), Brookfield viscosity from 752 to 903 Centipoise and penetration from 362 to $4321 / 10$ th $\mathrm{mm}$ at $25^{\circ} \mathrm{C}$ during the optimization process. From the analysis of variance, the $\mathrm{R}^{2}$ of all response variables is more than 0.77 that indicates that a high proportion of variability was explained by the model. Based on the response surface 3D plot of the sensory evaluation, the optimum acceptability of the Spirulina platensis incorporated soy yogurt processing parameter are at temperature of $40^{\circ} \mathrm{C}, 12 \mathrm{~h}$ of the fermentation duration and $0.80 \%(\mathrm{w} / \mathrm{w})$ of the Spirulina platensis.
\end{abstract}

Keywords: Spirulina platensis, sensory, viscosity, penetration, response surface methodology, soy yogurt

\section{INTRODUCTION}

Soy-yogurts have some adventages to consumers due to their hypolipidemic, anticholesterolemic and antiatherogenic properties as well as due to reduced allergenicity (Pourahmad and Ahanian, 2015). Protein content of soy yogurt and milk yogurt is similar $(3.5$ to $4.0 \%)$ and their amino acid pattern is fairly close except that soymilk is deficient in sulfur containing amino acids. Soy yogurt has about 60 to $90 \%$ nutritional value of milk yogurt and with adding small amounts of methionine to soy milk it has equivalent nutritional value to cow's milk (Abdullah et al., 2003). The high content of indigestible raffinose and stachyose, the flatulence factors, limit the consumption of soy yogurt (Tsai et al., 2006). Considerable research has been done to reduce off-flavors in soy yogurt by inhibiting formation of the isoflavones and lipid oxidation products responsible for them (Izadil et al, 2015)

Using Spirulina platensis can be desirable in producing beany odour free soy yogurt. Spirulina platensis has been shown to have many advantages, especially in terms of nutritional value and contains many valuable substances in the prevention and treatment of some diseases. Spirulina platensis has been used as a food source or supplement to provide nutrition and health improvements for people because it is rich in nutrients like protein, amino acid, essential fatty acids, vitamins and minerals. (Deng and Chow, 2010). In recent years, soy yogurts have been developed with expectedly enhanced nutritional superiority by incorporating functional lipids such as Gamma linolenic acid (GLA), Eicosapentaenoic acid (EPA) and Docosahexaenoic acid (DHA) and also providing specific antioxidants such as oryzanol and lignans through specific edible oils (Sengupta et al., 2013; Sengupta et al., 2016). Soy yogurts enriched with Spirulina platensis to provide higher arginine and methionine content in protein part and antioxidant such as selenium, zinc, tocopherol etc. (Morsy et al., 2014).

Soy yogurts have been used as the most popular carrier for incorporation of probiotic organisms (Beheshtipour et al., 2013). Unfortunately, most of the commercial products contain less probiotic bacteria than the minimum required, because these microorganisms grow slowly in milk and often show loss of viability during storage. In addition, the probiotic bacteria are sensitive to $\mathrm{pH}$ lactic acid, hydrogen peroxide, and dissolved oxygen in fermented milk (Zhao et al., 2006). Some researchers have observed that growth of lactic acid bacteria in synthetic media was promoted by Spirulina platensis extracellular product (De Caire et al., 2000). Therefore, it proved to be suitable for the cost-effective manufacture of novel functional fermented non-dairy yogurts. This addition will improve sensory characteristics of the final products.

To optimize process factors, an appropriate design of experiment was required, we were chosen response surface methodology (RSM) which was the key tool for reducing the number of experiments (Yaakob et al., 2012). It can help to optimize manufacturing processes involving multiple factors with different numbers of levels, especially fermentation processes and new Spirulina platensis incorporated soy yogurt developments, simultaneously and economically (Prabuthas et al., 2011). The application of RSM has not yet been adopted in studies related to soy yogurt supplemented with Spirulina platensis. Therefore, the aim of this work is to optimize the formulation ingredient and processing parameters of Spirulina platensis incorporated soy yogurt using RSM.

\section{MATERIAL AND METHODS}

All chemicals used were, purchased from MERCK, India. Soybean seeds were purchased from the local market (New Alipore Market, Kolkata West Bengal, India). Commercially available milk curd cultures were purchased from Microbial Type Culture Collection and Gene Bank, Chandigarh [Lactobacillus delbrueckii subsp. bulgaricus (MTCC 911) and Streptococcus thermophilus (MTCC 1938)]. Spirulina platensis was used as dry biomass having composition of protein $0.28 \mathrm{~g}$, energy $1.74 \mathrm{Kcal}$, fat $0.0 \mathrm{~g}$ and carbohydrate $0.16 \mathrm{~g}$ per $500 \mathrm{mg}$ (SUNOVA SPIRULINA, Surya Herbal Ltd. Noida,India). 


\section{Preparation of Spirulina platensis enriched soy yogur}

The soy milk was made according to the procedure described by Sengupta $\boldsymbol{e t}$ al., (2013). The resultant soymilk was then homogenized in a homogenizer (REM MOTORS-RQ-122) and pasteurized at $80^{\circ} \mathrm{C}$ for $15 \mathrm{~min}$. Soymilk was then cooled down to $40^{\circ} \mathrm{C}$ for the addition of Spirulina platensis. After addition of Spirulina platensis to pasteurized soy milk (1g of dry biomass of Spirulina platensis $100 \mathrm{ml}^{-1}$ of soy milk), the mixtures of soy milk and Spirulina platensis were homogenized again in a homogenizer prior to inoculation with starter culture until the Spirulina platensis was mixed properly throughout the soy milk Soy milk mixtures were aseptically inoculated with $2 \%$ of starter (Lactobacillus delbrueckii subsp. bulgaricus and Streptococcus thermophilus, 1:1 v/v). The inoculated soy milk containing the Spirulina platensis was then poured into 100 $\mathrm{ml}$ sterile transparent food grade plastic cups with lids and incubated at $37^{\circ} \mathrm{C}$ for $24 \mathrm{~h}$. Soy yogurts obtained were stored at $4^{\circ} \mathrm{C}$ in a refrigerator for further analyses. However the amount of Spirulina platensis, incubation temperature and duration were followed at certain level suggested by RSM.

Quantitative descriptive analysis of SP incorporated soy yogurt response variables

Sensory evaluation on the produced Spirulina platensis incorporated soy yogurt was conducted among 20-trained panelists in Indian Institute of Engineering Science and Technology, Shibpur. Samples of $5 \mathrm{ml}$ were put and served in a plastic container and coded alphabetically. The trained panelists evaluated all samples by marking the scale of intensity. Panelists were also served with a glass of water to neutralize the taste before analyzing the next sample. They were assisted in developing a consensus evaluation for sensory attributes for Spirulina platensis incorporated soy yogurt (Yaakob et al., 2012). Evaluation was done at Nine Point Hedonic Scale. The quality properties that were evaluated were appearance, aroma, texture $r$ and overall acceptance. The information contained on the sensory performance was indicated as $9=$ like extremely, $8=$ like very much, $7=$ like moderately, $6=$ like slightly, $5=$ neither like or dislike, $4=$ dislike slightly, $3=$ dislike, 2 =dislike very much, $1=$ dislike extremely.

\section{Experimental design and statistical analysis}

The statistical analysis of Spirulina platensis incorporated soy yogurt production was performed by using Design Expert (2000, V 6.0.8; Stat-Ease Inc., Minneapolis, MN, USA) software. Central composite design (CCD) was used to study the interaction of process variables by applying RSM (Bezerra et al. 2008). There are 3 variables which are temperature of fermentation process (X1), duration of fermentation (X2), and amount of Spirulina platensis (X3). Each variable has 3 different coded levels, from low $(-1)$, to medium $(0)$, and high $(+1)$ as well as the star points $(-\alpha$ and $+\alpha)$. The range of temperature is between 35 to $45^{\circ} \mathrm{C}, 8$ to $16 \mathrm{~h}$ for duration of fermentation and 0.1 to $1.5 \%(\mathrm{w} / \mathrm{w})$ for the amount of Spirulina platensis. The design matrix of Central Composite Design and also experimental results for the responses of Spirulina platensi incorporated soy yogurt are shown in Table 1. Taste (Y1), odor (Y2), color (Y3), appearance (Y4), and overall acceptability (Y5) were taken as the responses of the design experiment.

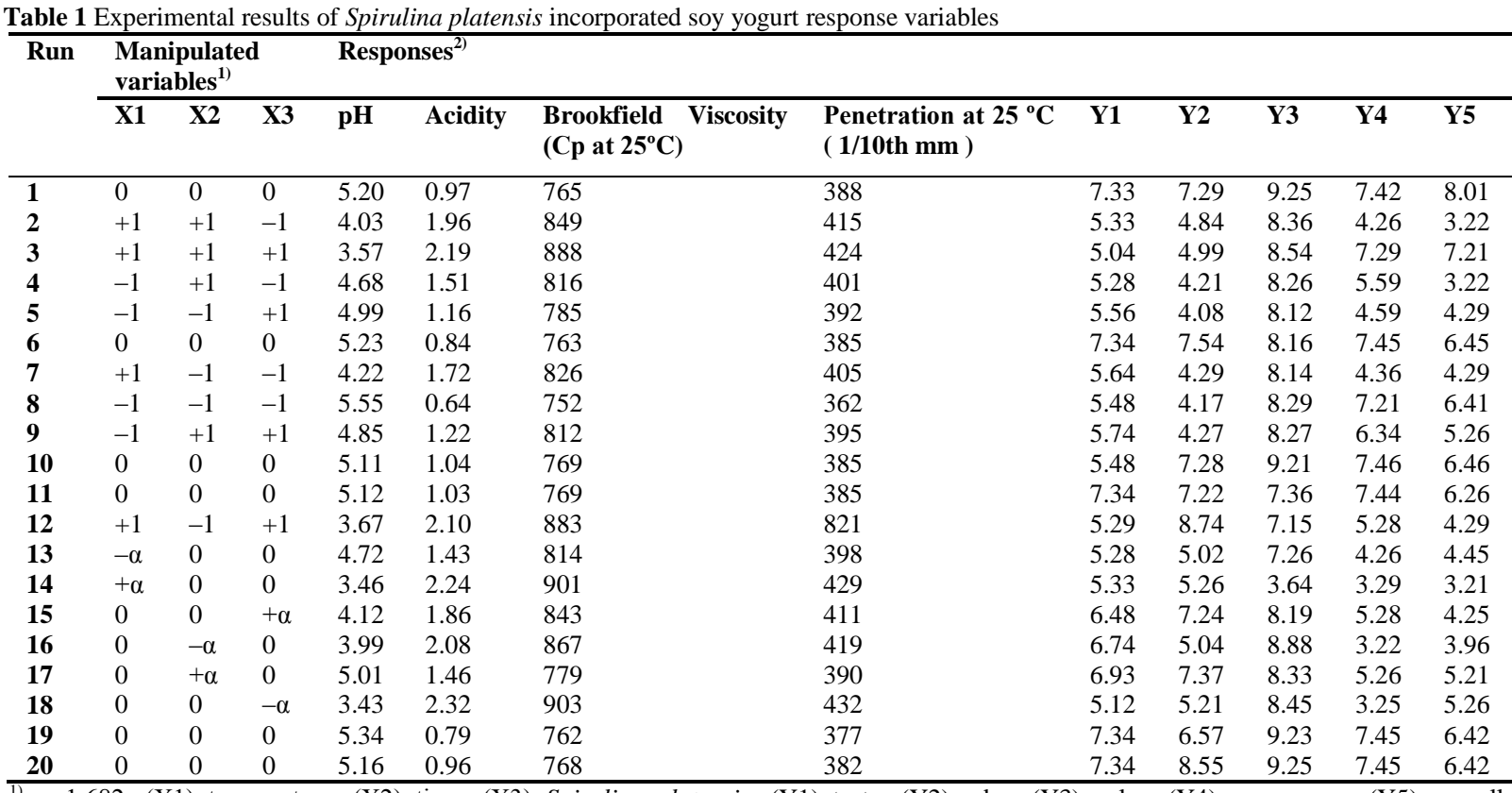

1) $\alpha=1.682$; (X1) temperature, (X2) time, (X3) Spirulina platensis, (Y1) taste, (Y2) odor, (Y3) color, (Y4) appearance, (Y5) overall acceptability

$\left.{ }^{2}\right)$ Using 9-point Hedonic scale

\section{Physicochemical analysis of Spirulina platensis incorporated soy yogurt}

The $\mathrm{pH}$ of the Spirulina platensis incorporated soy yogurt samples was measured directly using $\mathrm{pH}$ meter (Hanna $\mathrm{pH}$ meter No. 211). The Spirulina platensi incorporated soy yogurt samples were stirred with a $2.5 \mathrm{ml}$ of distilled water before $\mathrm{pH}$ measurement. The acid content of Spirulina platensis incorporated soy yogurt samples was determined according to AOAC, (2005) technique. Twenty grams of well homogenized sample was placed in a beaker and was titrated against $0.1 \mathrm{~N} \mathrm{NaOH}$ with phenolphthalein as indicator. Total Titratable acidity (TTA) was expressed as g equivalent lactic acid $100 \mathrm{~g}^{-1}$.

Viscosity was based on measuring resistance to a rotating spindle (Spindle No 3 at 20 RPM) Brookfield Model DV-E Viscometer at constant temperature $\left(25^{\circ} \mathrm{C}\right)$ for $5 \mathrm{~min}$. The sample was taken out from freezer $\left(-40^{\circ} \mathrm{C}\right)$ and was left at room temperature for $5 \mathrm{~min}$. Then, the sample was placed in a $10-\mathrm{mL}$ beaker and the spindle was dipped into the sample before the viscometer was switched on.Viscosity measurements were expressed in centipoises (cP) performed in Triplicate. The Viscosity determined with the Brookfield viscometer is known as the Brookfield Viscosity (Ozer et al., 1997).

Penetrometer Study The firmness of Spirulina platensis incorporated soy yogurts was determined by a Penetrometer (Stanhope-Seta Surrey, England) using the cone-form penetration body with an apical angle of $45^{\circ} \mathrm{C}$, and a weight of $72.5 \mathrm{~g}$. The depth of penetration was measured at $5 \mathrm{~s}$ at a product temperature of $25^{\circ} \mathrm{C}$

\section{RESULTS AND DISCUSSION}

\section{Model fitting for RSM}

The experimental results on the effect of temperature, time of fermentation, and amount of Spirulina platensis on the development of Spirulina platensis incorporated soy yogurt were shown in Table 1. The sensorial quality of the yogurt was evaluated as the responses for the factors studied. The quality of yogurt based on sensory evaluation was rated based on the taste, odor, color, appearance, and also the overall acceptability of the yogurt as responded by the panelists.

The results obtained from the ANOVA analysis are shown in Table 2. The F and $\mathrm{p}$-values of $\leq 0.05$ indicate that the quadratic model of the development of Spirulina platensis incorporated soy yogurt is statistically significant at $95 \%$ confidence interval. The lacks of fit for each response were insignificant. The $\mathrm{R}^{2}$ values for the appearance exceeding $90 \%$, which indicated that a high proportion of variability was well explained by the model while taste, aroma color and and overall acceptability show high values of $\mathrm{R}^{2}$ was around $77.81 \%, 77.48 \%$, $79.39 \%$ and $82.56 \%$ respectively indicating that only $22.19 \%$ for taste, $22.52 \%$ for aroma, $20.61 \%$ for color and $17.44 \%$ for overall acceptability of the data could not be interpreted by the model. 
Table 2 Analysis of variance of the response variables ${ }^{*}$

\begin{tabular}{|c|c|c|c|c|c|c|c|}
\hline & Source & Sum of square & DF & Mean square & F value & Prob $>$ F & $\overline{\mathbf{R}^{2}(\%)}$ \\
\hline \multirow{4}{*}{ Taste } & Model & 11.46 & 9 & 1.27 & 3.51 & 0.0378 & 77.81 \\
\hline & Lack of fit & 0.68 & 5 & 0.14 & 0.21 & 0.9407 & \\
\hline & Pure error & 2.59 & 4 & 0.65 & & & \\
\hline & Total & 15.56 & 19 & & & & \\
\hline \multirow{4}{*}{ Aroma } & Model & 34.91 & 9 & 3.88 & 3.44 & 0.0399 & 77.48 \\
\hline & Lack of fit & 8.16 & 5 & 1.63 & 3.22 & 0.1403 & \\
\hline & Pure error & 2.02 & 4 & 0.51 & & & \\
\hline & Total & 46.45 & 19 & & & & \\
\hline \multirow{4}{*}{ Colour } & Model & 21.87 & 9 & 2.43 & 3.85 & 0.0286 & 79.39 \\
\hline & Lack of fit & 4.83 & 5 & 0.97 & 4.55 & 0.0836 & \\
\hline & Pure error & 0.85 & 4 & 0.21 & & & \\
\hline & Total & 28.80 & 19 & & & & \\
\hline \multirow{4}{*}{ Appearance } & Model & 48.41 & 9 & 5.38 & 13.06 & 0.0004 & 92.89 \\
\hline & Lack of fit & 2.92 & 5 & 0.59 & 3.18 & 0.1428 & \\
\hline & Pure error & 0.75 & 4 & 0.19 & & & \\
\hline & Total & 63.53 & 19 & & & & \\
\hline \multirow{4}{*}{$\begin{array}{c}\text { Overall } \\
\text { acceptability }\end{array}$} & Model & 28.20 & 9 & 3.13 & 4.73 & 0.0150 & 82.56 \\
\hline & Lack of fit & 3.96 & 5 & 0.79 & 1.59 & 0.3369 & \\
\hline & Pure error & 1.99 & 4 & 0.50 & & & \\
\hline & Total & 34.59 & 19 & & & & \\
\hline
\end{tabular}

\section{Physico-chemical properties of Spirulina platensis incorporated soy yogurt}

The value of $\mathrm{pH}$, acidity, viscosity and penetration of freshly prepared Spirulina platensis incorporated soy yogurt were measured and the results were illustrated in Table 1. Generally, the changes of physico-chemical properties of Spirulina platensis incorporated soy yogurt were affected by the level of processing condition. The $\mathrm{pH}$ of the Spirulina platensis incorporated soy yogurt ranged from 3.43 to 5.55 (average $\mathrm{pH}$ of 4.57 ). Run 18 produced the lowest value of $\mathrm{pH}$ at 3.43. Meanwhile, run 8 with a coded condition of $(-1,-1,-1)$ showed the highes value at 5.55. The different values of $\mathrm{pH}$ might due to the metabolic activities of the Spirulina platensis in the soy yogurt with lactic acid bacteria. Researchers had stated that the value of $\mathrm{pH}$ is inversely proportional to the lactic acid content in Spirulina platensis incorporated soy yogurt (Kavimandan and Sharma, 2015). Total acidity of the Spirulina platensis incorporated soy yogurt ranged from 0.64 to $2.32(\%)$. Osundahunsi et al., (2007) reported that minimum value of acidity in soy yogurt is 1.00 to $1.99 \%$ and maximum formulations tested were successfully achieving the minimum value. From the result, the acidity of the yogurt was also controlled by the processing factors. The acid content of Spirulina platensis incorporated soy yogurt will be higher if the fermentation was carried out at $40^{\circ} \mathrm{C}$ temperature, for $12 \mathrm{~h}$ using $0.8 \%$ (w/w) starter culture.

In order to prevent over-acidification, the amount of Spirulina platensis needed to be controlled (Champagne and Mollgaard, 2008). Over acidification was probably caused from the addition of powdered Spirulina platensis which promoted the growth of lactic acid bacteria (Mocanu et al.,2013).Selecting amount of Spirulina platensis was the most important aspect to consider in overcoming excessive acid production. The appropriate $\mathrm{pH}$ and temperature during processing need to be identified because both parameters will affect the activity of lactic acid bacteria. The rheological analysis of product did not show any significant effect on Spirulina platensis added products. No difference was observed in the shear stress and dynamic viscosity of fluid. Another way to prevent excess acidification was to reduce the refrigeration temperature to slow down the growth of the Spirulina platensis. However, Guldas and Irkin (2010) showed the positive effect of Spirulina platensis powder on the survival of the lactic acid bacteria during storage of yogurt. At refrigerated temperature activity of lactic acid bacteria was also reduced. Therefore, as indicated through this study, the combination level of processing parameter was really important to obtain appropriate acidity of Spirulina platensis incorporated soy yogurt.

The results showed that again different level of processing parameter gave different level of viscosity and penetration. For example, the viscosity and the penetration of Spirulina platensis incorporated soy yogurt showed that soy yogurt with the temperature higher than $37^{\circ} \mathrm{C}$, incubation longer than $12 \mathrm{~h}$, and amount of Spirulina platensis $0.8 \%$ (w/w) was more viscous compared to the Spirulina platensis incorporated soy yogurt with other processing level combination. The acidity of this yogurt was high and it seems that the viscosity and penetration of the Spirulina platensis incorporated soy yogurt depends on the acid production. This was because, when the acidity increased, the protein present in Spirulina platensis incorporated soy milk will form more gel resulting soy yogurt with high viscosity and penetration (Lordan et al., 2011).

\section{Effect of processing parameter on the sensory evaluations}

The effect of temperature (X1), time of fermentation (X2), and amount of Spirulina platensis (X3) on the sensorial quality of the Spirulina platensis incorporated soy yogurt was represented by the quadratic model and is also aided by the response surface plots for better visualization shown in Fig 1-5. The sensory scores for taste, odor, color, appearance, and overall acceptability of the
Spirulina platensis incorporated soy yogurt were shown in Table 1. Fig 1-5 clearly visualizes that temperature, time of fermentation, and amount of Spirulina platensis affected the quality of the Spirulina platensis incorporated soy yogurt.The response surface plot for the taste of the Spirulina platensis incorporated soy yogurt was shown in Fig 1. For the overall acceptability of the yogurt taste, it was shown that the response was more towards 'like slightly' and 'like very much' which was numerically in the range of 5.82 to 8.52 . As is evident in Fig 1 the temp, time and amount of Spirulina platensis induced an increase of taste score at low levels, whereas at higher levels, the taste score decreased with higher the temp, time and amount of Spirulina platensis .Such a trend might be explained due to increased overrun and intense green colour. Though the growth of probiotic bacteria populations in the fermented functional foods were much higher in the presence of the Spirulina platensis than when the probiotics were grown alone, addition of Spirulina platensis higher than $0.8 \%$ might be the causes for decreased overall acceptability of the product.
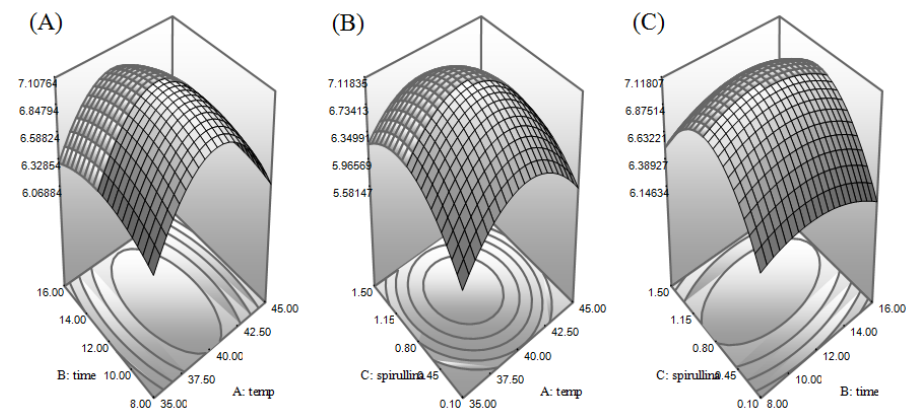

Fig 1 Response surface plot of the effects of temperature and time (A), temperature and amount of Spirulina platensis (B), and time and amount of Spirulina platensis (C) on the taste of Spirulina platensis incorporated soy yogurt

Soy yogurt smell was taken into consideration in the development of Spirulina platensis incorporated soy yogurt. The results had shown in Fig 2 exhibited that panelists like the smell of these Spirulina platensis incorporated soy yogurts. The aroma was found to be most dependent on Spirulina platensis content rather than time and temp. Higher Spirulina platensis and lower time and temp resulted higher aroma in the studied experimental range. The steady increase in aroma with increasing Spirulina platensis could be due to the addition of increasing amounts of protein to the blend which may affect the extent of lactic acid fermentation. 

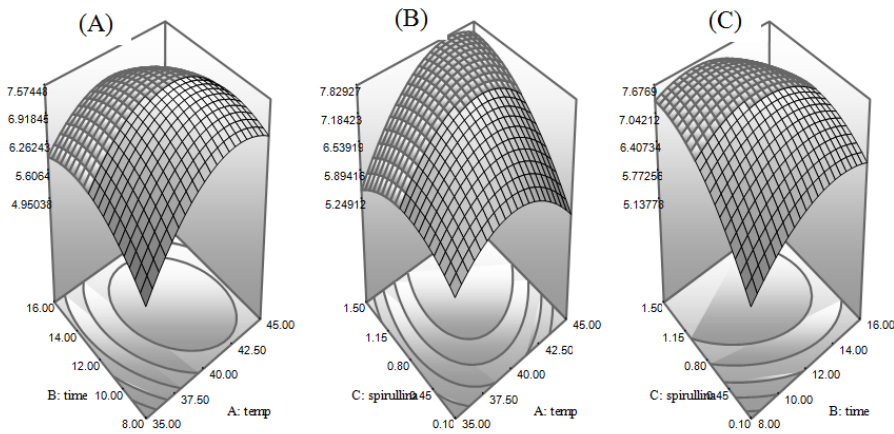

Fig 2 Response surface plot of the effects of temperature and time (A), temperature and amount of Spirulina platensis (B), and time and amount of Spirulina platensis (C) on the aroma of Spirulina platensis incorporated soy yogurt

The response surface plot for the color of Spirulina platensis incorporated soy yogurt was shown in Fig 3. With regard to the color data, all assays garnered mean hedonic scores ranging from 'moderately liked' to 'extremely liked' Formulation 1 and 20 were given the best score for this attribute. A non-dairy soy yogurt containing Spirulina platensis received $82.56 \%$ of acceptance indicating that consumers were beginning to overcome the negative opinions they once held regarding soy-containing products not only due to the health benefits they may confer, but also because of their good taste, color and aroma.
(A)

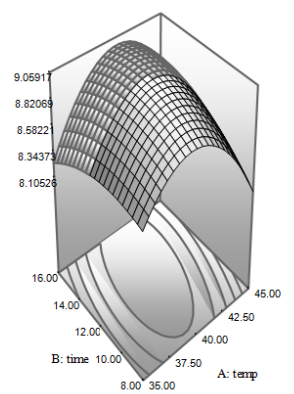

(B)

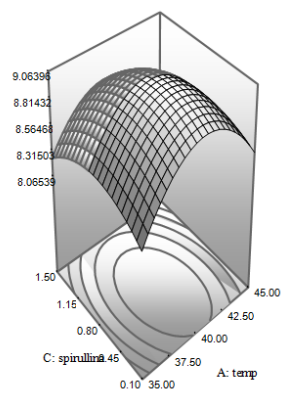

(C)

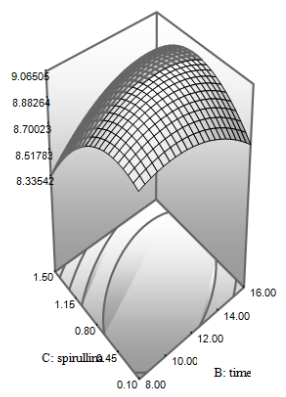

Fig 3 Response surface plot of the effects of temperature and time (A) temperature and amount of Spirulina platensis (B), and time and amount of Spirulina platensis (C) on the color of Spirulina platensis incorporated soy yogurt

The scopes of analysing the appearance characteristics of the Spirulina platensis incorporated soy yogurt prioritiesed its texture was shown in Fig 4. In order to produce Spirulina platensis incorporated soy yogurt with good appearance, the temperature range required is between 38.94 to $40.08^{\circ} \mathrm{C}$, and time of between 8 to $13.51 \mathrm{~h}$. This was observed for formulation 10 with the highest response of 7.46 (Table 1). Furthermore, the medium amount of starter culture (1.04 to 1.34 $\%$ ) in this formulation could contribute to a better texture. The increase in appearance with increase in level of incorporation at 1.04 to $1.34 \%$ level is mainly due to beneficial influence of Spirulina platensis on the survival of lactic acid bacteria owing to its high protein, esential fatty acids such as gamma linolenic acid, vitamins and minerals (Perez et al., 2007) lower whey separation due to lower acidity and intense green colour.
(A)

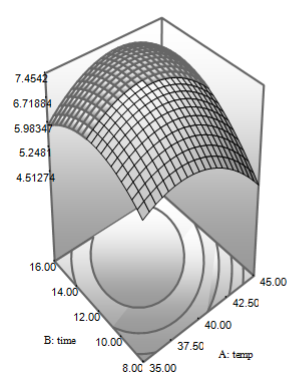

(B)

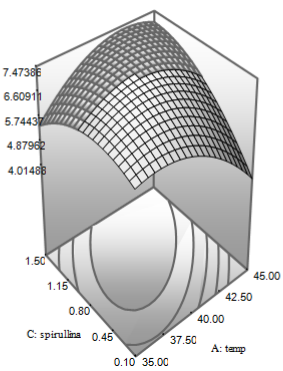

(C)

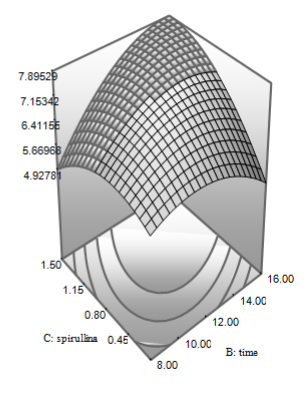

Fig 4 Response surface plot of the effects of temperature and time (A), temperature and amount of Spirulina platensis (B), and time and amount of Spirulina platensis (C) on the appearance of Spirulina platensis incorporated soy yogurt
The overall acceptability of the of Spirulina platensis incorporated soy yogurt priorities as affected by the temperature, time, and amount of Spirulina platensis with positive and negative quadratic effects at $\mathrm{p} \leq 0.05$ were shown in Fig 5 Productions at the temperature of $39.62^{\circ} \mathrm{C}$, time of $12.38 \mathrm{~h}$ and of Spirulina platensis of $0.95 \%(\mathrm{w} / \mathrm{w})$, indicated the optimum overall acceptability of 6.59 This showed that temp, time and starter culture are important parameters for Spirulina platensis incorporated soy yogurt acceptability. Hence, it was proven that the optimized region for overall acceptability of this of Spirulina platensis incorporated soy yogurt by the panelists was between the ranges of 'like slightly' and 'like moderately'.
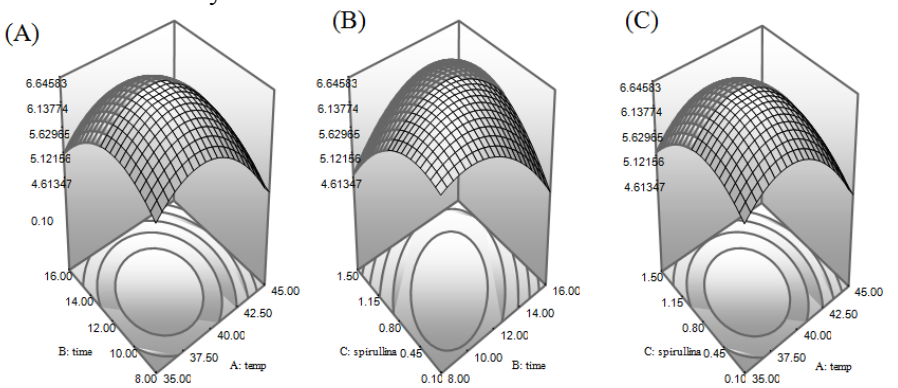

Fig 5 Response surface plot of the effects of of temperature and time (A), temperature and amount of Spirulina platensis (B), and time and amount of Spirulina platensis (C)on the overall acceptability of Spirulina platensis incorporated soy yogurt

\section{CONCLUSION}

RSM was successfully optimized for the ingredient formulation and processing parameter of Spirulina platensis incorporated soy yogurt. In general, the optimized value obtained from the RSM is different from the data calculated at Table 1. This is because the optimization has been carried out by the software and the variables in the range have been selected to obtain the optimum response. Based on the response surface 3D plot of the sensory evaluation, the optimum acceptability of the Spirulina platensis incorporated soy yogurt processing parameter are at temperature of $40^{\circ} \mathrm{C}, 12 \mathrm{~h}$ of the fermentation time, and at $0.80 \%(\mathrm{w} / \mathrm{w})$ of the Spirulina platensis. Future studies to identify the active ingredients in Spirulina platensis incorporated soy yogurt and uncover the mechanistic insights into Spirulina platensis incorporated soy yogurt's medicinal effects will provide the bases for developing new non-dairy food products for preventing or treating hypercholesterolemia and cardiovascular diseases.

\section{REFERENCES}

AOAC (2005). Official Methods of Analysis of AOAC International, 18th ed Maryland: AOAC International.

Abdullah, M., Saleem-ur-Rehman, Z. H., Saeed, H.M., Kousar, S \& Shahid, M (2003). Effect of Skim Milk in Soymilk Blend on the Quality of Ice Cream. Pak. J. Nutr, 2 (5), 305-311.

Beheshtipour, H., Mortazavian, A. M., Mohammadi, R., Sohrabvandi, S., \& Khosravi-Darani, K. (2013) Supplementation of Spirulina platensis and Chlorella vulgaris Algae into Probiotic Fermented Milks. Comp Rev Food Sci Food, 12 144-154. http://dx.doi.org/10.1111/1541-4337.1

Bezerra, M., Santelli, R, Oliveira, E., Villar, L., \& Escaleira, L. (2008). Response surface methodology (RSM) as a tool for optimization in analytical chemistry.

Talanta, $7^{<}$^re ถา . http://dx.doi.org/10.1016/j.talanta.2008.05.019

Champagr (C) Mollgaard, H. (2008): Production of probiotic cultures and their addit ented foods. Handbook of Fermented Functional Foods, 2nd Edition, (Edited by E.R. Farnworth), CRC Press, Boca Raton, FL, USA.

De Caire, G.Z., Parada, J.L., Zaccaro, M.C., \& de Cano, M.M.S. (2000). Effect of Spirulina platensis biomass on the growth of lactic acid bacteria in milk. World $J$ Microbiol Biotechnol, 16, 563-565.

Deng, R., \& Chow, T.J. (2010). Hypolipidemic, Antioxidant and Antiinflammatory Activities of Microalgae Spirulina. Cardiovascular

Therapeutics, 28(4), 33-45. http://doi.org/10.1111/j.1755-5922.2010.00200.x

Guldas, M., \& Irkin, R.. (2011). Microflora of yoghurt and acidophilus milk, Mljekarstvo, 60 (4), 237-243.

Izadi, T., Izadi, Z., Tehrani, M.M., Ali P.M., Moghadam, M.Z., \& Shariaty, M.A (2013).Investigation of Optimized Methods for Improvement of Organoleptical and Physical Properties of Soy milk. Intl J Farm \& Alli Sci., 2 (10), 245-250

Kavimandan, A., \& Sharma S. (2015). Role of Spirulina platensis as an enhancer of probiotic organisms in whey. International journal of dairy science research, $3(1), 1-6$ 
Lordan, S., Ross, R. P., \& Stanton, C. (2011). Marine Bioactives as Functional Food Ingredients: Potential to Reduce the Incidence of Chronic Diseases.Marine

Drugs, 9(6), 1056-1100. http://dx.doi.org/10.3390/md9061056

Mocanu, G.D., Botez, E., Nistor, O.V. Andronoiu D.G., Vlăsceanu, G. (2013).Influence of Spirulina platensis biomass over some starter culture of lactic bacteria. Journal of Agroalimentary Processes and Technologies, 19(4), 474-479. Morsy, O.M., Sharoba, A.M., EL-Desouky, A.I., Bahlol, H.E.M. \& Abd El Mawla, E.M. (2014).Production and evaluation of some extruded food products using spirulina algae. Annals of Agric. Sci., 52(4) 329-342.

Osundahunsi, O.F., Amosu, D., \& Ifesan, B.O.T. (2007). Quality Evaluation and Acceptability of Soy-yoghurt with Different Colours and Fruit Flavours. Am. J Food Technol., 2, 273-280. http://dx.doi.org/10.3923/ajft.2007.273.280

Özer, B., Robinson, R.K., Grandison, A.S. \& Bell A.E. (1997). Comparison of Techniques for Measuring the Rheological Properties of Labneh (Concentrated Yogurt). International Journal of Dairy Technology, 50(4), 129-133. http://dx.doi.org/10.1111/j.1471-0307.1997.tb01753.x

Perez, K.I., Guarenti, C., Bortelil, T.E., Costa, J.A.V.E. \& COLLA, L.M. (2007).

Effect of adding dry biomass of the spirulina platensis to yogurt on the survival of lactic acid bacteria during refrigerated stogie. Alim. Nutr., 18 (1) , 77-82.

Pourahmad, R. \& Ahanian, B. (2015). Production of cocoa flavored soymilk ice cream. WALIA, 31 (S4), 242-248.

Prabuthas, P., Srivastav, P.P., \& Mishra, H.N. (2011).Optimization of environmental factors using RSM for Spirulina platensis cultivation. Nutr. Food Sci., 41 (3), 175-182. http://dx.doi.org/10.1108/00346651111132448

Sengupta, S., Bhowal, J., \& Bhattacharyya, D.K. (2013). Development of new kinds of Soy yogurt containing functional lipids as superior quality food. Annals of Biological Research, 4,144-151.

Sengupta, S., Goswami, R., Basu, S., \& Bhowal, J. (2016). Hypolipidemic effects of soy yogurt fortified with antioxidant rich vegetable oil on albino mice fed high cholesterol diet. Materials Today: Proceeding, 3 (2016), 3222-3237. http://dx.doi.org/10.1016/i.matpr.2016.10.004

Tsai, J.S. Lin, Y.S. Pan, B.S. \& Chen, T.J. (2006). Antihypertensive peptides and g-aminobutyric acid from prozyme 6 facilitated lactic acid bacteria fermentation of soymilk. Process Biochem, 41, 1282-1288.

Yaakob, H., Ahmed, N. R., Daud, S. K., Malek, R. A., \& Rahman, R.A. (2012) Optimization of Ingredient and Processing Levels for the Production of Coconut Yogurt Using Response Surface Methodology. Food Sci. Biotechnol., 21(4), 933-940. http://dx.doi.org/10.1007/s10068-012-0123-0

Zhao, Q.Z., Wang, J.S., Zhao, M.M., Jiang, Y.M, \& Chun, C. (2006). Effect of casein hydrolysates on yogurt fermentation and texture properties during storage. Food Technol Biotechnol, 44 (3), 429-34. 